\title{
What are people willing to pay for whole-genome sequencing information, and who decides what they receive?
}

\author{
Deborah A. Marshall, PhD'1, Juan Marcos Gonzalez, PhD², F. Reed Johnson, PhD, \\ Karen V. MacDonald, MPH${ }^{1}$, Amy Pugh, BA ${ }^{2}$, Michael P. Douglas, MS ${ }^{4}$ and Kathryn A. Phillips, PhD ${ }^{5,6}$
}

\begin{abstract}
Purpose: Whole-genome sequencing (WGS) can be used as a powerful diagnostic tool as well as for screening, but it may lead to anxiety, unnecessary testing, and overtreatment. Current guidelines suggest reporting clinically actionable secondary findings when diagnostic testing is performed. We examined preferences for receiving WGS results.
\end{abstract}

Methods: A US nationally representative survey ( $n=410$ adults) was used to rank preferences for who decides (an expert panel, your doctor, you) which WGS results are reported. We estimated the value of information about variants with varying levels of clinical usefulness by using willingness to pay contingent valuation questions.

Results: The results were as follows: $43 \%$ preferred to decide themselves what information is included in the WGS report. 38\% (95\% confidence interval (CI): 33-43\%) would not pay for actionable variants, and 3\% (95\% CI: $1-5 \%$ ) would pay more than $\$ 1,000.55 \%$ (95\% CI: $50-60 \%$ ) would not pay for variants for which medical treatment is currently unclear, and 7\% (95\% CI: 5-9\%) would pay more than $\$ 400$.

Conclusion: Most people prefer to decide what WGS results are reported. Despite valuing actionable information more, some respondents perceive that genetic information could negatively impact them. Preference heterogeneity for WGS information should be considered in the development of policies, particularly to integrate patient preferences with personalized medicine and shared decision making.

Genet Med advance online publication 2 June 2016

Key Words: attitude to health; health-care costs; secondary findings; whole-genome sequencing; willingness to pay

\section{INTRODUCTION}

Whole-genome sequencing (WGS) determines the complete DNA sequence of an individual and can be used as a powerful diagnostic tool. ${ }^{1,2}$ Applied in the general population, it could be used for screening. ${ }^{2-4}$ Unlike whole-exome sequencing, which targets the protein-coding regions of the genome $(<2 \%$ of the genome), WGS involves sequencing the whole genome (coding, noncoding, and mitochondrial DNA). ${ }^{5}$ Results from WGS include primary findings (variants in a gene(s) relevant to the diagnostic indication for which sequencing was ordered) and secondary findings (also termed incidental findings; variants in genes not apparently relevant to a diagnostic indication for which sequencing was ordered). ${ }^{6}$ In 2013, the American College of Medical Genetics and Genomics (ACMG) recommended that only secondary finding variants currently determined to be clinically actionable be reported when sequencing is ordered for a primary indication. ${ }^{6}$

In 2015 , the recommendations were updated to address the critical issue of who decides what results should be included in the WGS report. The new guidelines recommend that "patients should be able to opt out of the analysis of genes unrelated to the indication for testing."' Reporting secondary findings currently determined to have unclear medical treatment could generate anxiety and unnecessary medical tests, but patients could miss valuable information if not reported ${ }^{8,9}$ Furthermore, prematurely acting on findings may result in overtreatment, potentially causing harm and unnecessary use of health-care resources. ${ }^{8,9}$ However, individuals may want to learn about these findings in order to reassess personal priorities and/or get affairs in order if their chance of death is increased, or they may hope that information regarding long-term risk becomes actionable in the future. Clinical genome or exome sequencing is currently indicated for the detection of rare variants in patients seeking a diagnosis for a potential Mendelian genetic disorder, and several thousand tests have already been ordered for this population. ${ }^{4}$ As costs decrease, it is possible that WGS will become more routine and possibly used for screening in the general population..$^{1,2,4,10}$ The ACMG recommends that when

\footnotetext{
${ }^{1}$ Department of Community Health Sciences, University of Calgary, Calgary, Alberta, Canada; ${ }^{2}$ Research Triangle Institute, Research Triangle Park, North Carolina, USA; ${ }^{3}$ Duke Clinical Research Institute, Duke University, Durham, North Carolina, USA; ${ }^{4}$ Department of Clinical Pharmacy, Center for Translational and Policy Research on Personalized Medicine (TRANSPERS), University of California at San Francisco, San Francisco, California, USA; ${ }^{5}$ UCSF Philip R. Lee Institute for Health Policy, University of California at San Francisco, San Francisco, California, USA; ${ }^{6}$ UCSF Helen Diller Family Comprehensive Cancer Center, University of California at San Francisco, San Francisco, California, USA. Correspondence: Deborah A. Marshall (Damarsha@ucalgary.ca)
} 
WGS is used for diagnostic purposes, the individual tested (or their guardian) undergo informed-consent procedures regarding possible secondary findings in 56 genes for conditions that "have a high likelihood of severe disease that is preventable if identified before symptoms occur." Costs of genome sequencing data range from US $\$ 4,000$ to $\$ 15,000$ and can vary depending on interpretation and volume of data., ${ }^{4,11}$

Whether WGS can achieve its potential to improve patient outcomes will depend on what information is given to patients and how patients and providers respond to and value the information provided. From a health-care-system perspective, the benefits and costs of WGS will depend on short- and longterm consequences associated with receiving WGS information, guidelines' recommendations with respect to ordering WGS, and whether the cost of WGS will be covered by payers. Assessing the value of WGS is complex because the technique provides not just one test result but multiple results that have varying levels of clinical usefulness (Table 1). Actionable findings are variants that are considered clinically useful and can be acted on (i.e., variants for which there are medical treatment guidelines or that are associated with preventable diseases). ${ }^{12,13}$ Findings for which evidence for best clinical action is not available are variants that are considered clinically valid but do not meet as high a standard for clinical usefulness (i.e., variants for which there is unclear medical treatment). Findings of unknown significance are variants considered to have unknown or no clinical significance. These variants are not "strongly linked to a phenotype, clinical outcome, or intervention." ${ }^{12,13}$

There are several methods for estimating value and personal utility. In genomics, personal utility is defined as the meaning and worth an individual gives to a genomic or genetic test from their personal perspective. ${ }^{10,14}$ Cost-effectiveness, using an incremental cost-effectiveness ratio, is one approach to capturing value, typically from a health-care-system and payer perspective, to inform resource-allocation decisions. ${ }^{15}$ Contingent valuation is a survey-based method used for valuation of nonmarket services (e.g., health treatments) to estimate willingness to pay in monetary units (with a range and maximum amount). ${ }^{16}$ Contingent valuation can be used to estimate personal utility and the value of WGS information.

Previous research suggests that individuals, regardless of health status, value having choices about the WGS information they receive, and many clinicians believe that people should have a choice about the results they receive. ${ }^{17-20}$ However, there is limited evidence pertaining to the willingness to pay for
WGS information, depending on whether that information is medically actionable, or who should decide what results are included and returned in a WGS report. In this study, we elicited preferences regarding who defines which WGS results are included in a WGS report to help inform health policy, and we estimated the value of WGS information using contingent-valuation methods to determine willingness to pay in a nationally representative sample of adults from the US general population.

\section{MATERIALS AND METHODS}

\section{Study design}

We designed an online survey to elicit stated preferences for receipt of WGS information in the context of screening for pathogenic variants. The survey included the following sections:

1. A ranking exercise to elicit preferences for who defines which WGS results are included in a genomic report

2. Contingent-valuation questions to elicit willingness to pay for a basic genomic report that includes only actionable genomic status information (based on ACMG recommendations $)^{6}$

3. Contingent-valuation questions to elicit willingness to pay for genomic information for which the medical treatment is currently unclear and would not be included in a basic genomic report (based on ACMG recommendations)

Our survey development was informed by a literature review of attitudes, values, and preferences in genomic/genetic testing; pretest interviews and cognitive testing (using one-on-one "think aloud" methods) with 13 consecutive adults who were enrolled in the MedSeq study (U01-HG006500) at the time of baseline data collection; ${ }^{2,21}$ and consultation with our team of genetics experts. Risks were explained in words as follows: chance of having a gene variant that leads to health problems, chance of having additional gene variants that are not included in a genome report, and chance of death in the next 10 years if you have one of the additional gene variants. For each risk, a probability was expressed as a number and a diagram (e.g., chance of having any of the additional gene variants is 1 out of $100(1 \%))$. The diagram of the probability had 100 dots with a colored dot or dots to express the probability out of 100 , and the remaining dots were gray. The costs presented to respondents in the contingent-valuation questions were based on a review of the cost of WGS in the United States in 2014, and the upper

Table 1 Summary and examples of actionable findings, findings for which evidence for best clinical action is not available, and findings of unknown significance

\begin{tabular}{ll} 
Actionable findings & $\begin{array}{c}\text { Findings for which evidence for the best } \\
\text { clinical action is not available }\end{array}$ \\
\hline $\begin{array}{l}\text { Variants that are considered to be clinically useful } \\
\text { and can be acted on (i.e., variants with medical } \\
\text { treatment guidelines or preventable diseases), }\end{array}$ & $\begin{array}{l}\text { Variants that are considered clinically valid but } \\
\text { do not meet as high of a standard for clinical } \\
\text { usefulness (i.e., variants for which there is unclear } \\
\text { medical treatment), }\end{array}$ \\
$\begin{array}{ll}\text { for example, hereditary breast and ovarian cancer } \\
\text { or Lynch syndrome }\end{array}$ & $\begin{array}{l}6,12,13 \\
\text { for example, APOE4 allele associated with } \\
\text { Alzheimer disease risk or Huntington disease }\end{array}$ \\
\end{tabular}

Findings of unknown significance

Variants that are considered to have an unknown or no clinical significance; these variants are not "strongly linked to a phenotype, clinical outcome, or intervention" 12,13 
levels were informed by maximum willingness to pay stated in pretest interviews.

For the ranking exercise, respondents were asked to rank three mutually exclusive options from 1 to 3 (where 1 was the most desirable option and 3 was the least desirable) for defining the results included in the genomic report:

Option 1. A panel of experts decides which variants to include: a report that includes results only for gene variants that could lead to health problems that a panel of experts is sure can be prevented or treated.

Option 2. Your doctor decides which variants to include: a report your doctor chooses based on your family history and the information he or she thinks you would find useful. Your doctor could explain the results that you get with this report, but you would not necessarily know how this report is different from the experts' genome report.

Option 3. You decide which variants to include: a report that includes results for gene variants you choose based on your own understanding and concerns about your chance of health problems and possible treatments.

The survey included the following description about the information that the respondents would receive from WGS in a basic genomic report in the context of using WGS as a screening tool for pathogenic variants:

Based on the recommendations of experts, people who sequence their genome receive a report on whether they have any one of hundreds of gene variants that lead to health problems. About 1\% (1 out of 100) of people learn that they have at least one of the gene variants included in the genome report. If you have any of the gene variants included in the genome report, you can get information about your chance of getting health problems that can be prevented or treated, and information about the chance that your children or family members have health problems.

Following the WGS report description, respondents were asked contingent-valuation questions to elicit their willingness to pay for genomic information. We used a double-bounded dichotomous choice elicitation format to vary the initial WGS report cost across respondents (two-question bidding game; Figure 1 and Supplementary Appendix A online), which has been widely used to value public goods, including health. ${ }^{16,22}$

In the first set of double-bounded contingent-valuation (DBCV) questions, respondents were randomly assigned to one of two initial basic report costs $(\$ 1,000$ or $\$ 500)$. The cost was doubled if the respondent answered "yes" to the initial report cost and halved if the respondent answered "no." If a respondent rejected the report cost a second time, the cost was set to $\$ 0$. In the second set of DBCV questions, respondents were randomly assigned to one of two initial costs ( $\$ 400$ or $\$ 200)$ for the additional genomic information for which the medical treatment is currently unclear. The cost doubled if the respondent answered "yes" to the initial cost, and halved if the respondent answered "no." If a respondent rejected the additional genomic information cost a second time, the cost was set to $\$ 0$.

\section{Statistical methods}

We calculated the proportion of respondents (and 95\% confidence interval (CI)) who chose as their first preference which WGS results are reported (expert panel, your doctor, you). We used a rank-ordered logit regression model to analyze the ranking of options. ${ }^{23}$

Only answers from respondents who stated they would be willing to accept genomic information were considered in the analysis, implicitly conditioning the willingness-to-pay estimation to represent the value of information among those who wanted WGS reports. To analyze the DBCV questions,
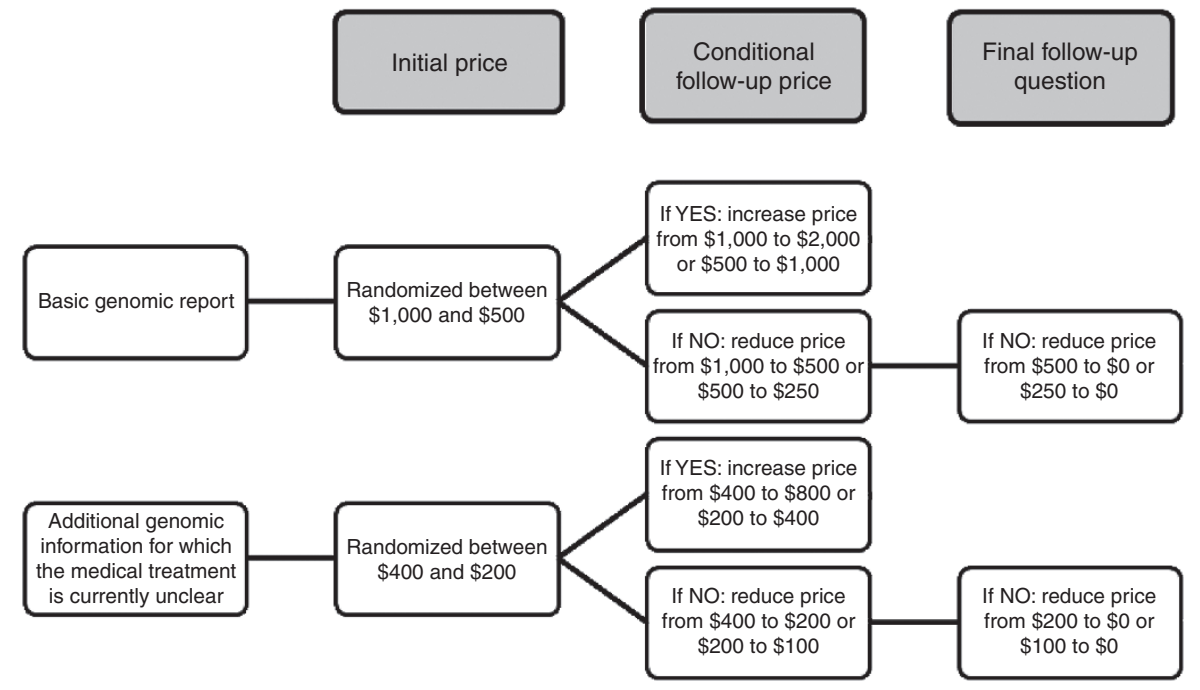

Figure 1 Bid structure used for double-bounded contingent-valuation questions eliciting willingness to pay. The options are a basic genomic report that includes only actionable genomic status information and additional genomic information for which the medical treatment is currently unclear. 
Table 2 Demographics and other respondent characteristics $(n=410)$

\begin{tabular}{|c|c|c|}
\hline Characteristic & Unweighted summary ${ }^{a}$ & Weighted summary \\
\hline \multicolumn{3}{|l|}{ Age (years) } \\
\hline Median (SD) & $50(17)$ & $48(17)$ \\
\hline Range & $21-91$ & $21-91$ \\
\hline \multicolumn{3}{|l|}{ Gender, $n(\%)$} \\
\hline Male & $218(53 \%)$ & $197(48 \%)$ \\
\hline Female & $192(47 \%)$ & $213(52 \%)$ \\
\hline \multicolumn{3}{|l|}{ Marital status, $n(\%)$} \\
\hline Married/living with partner & $261(64 \%)$ & $252(61 \%)$ \\
\hline Widowed/divorced/separated/never married & $149(36 \%)$ & $158(39 \%)$ \\
\hline \multicolumn{3}{|l|}{ Education, $n(\%)$} \\
\hline Less than high school/high school & $148(36 \%)$ & $169(41 \%)$ \\
\hline Some college & $121(30 \%)$ & $115(28 \%)$ \\
\hline Bachelor's degree or higher & $141(34 \%)$ & $126(31 \%)$ \\
\hline \multicolumn{3}{|l|}{ Employment, $n(\%)$} \\
\hline Employed & $242(59 \%)$ & $236(58 \%)$ \\
\hline Not employed & $168(41 \%)$ & $174(42 \%)$ \\
\hline \multicolumn{3}{|l|}{ Race/ethnicity, $n(\%)$} \\
\hline White, non-Hispanic & $287(70 \%)$ & $271(66 \%)$ \\
\hline Black, non-Hispanic & $44(11 \%)$ & $47(11 \%)$ \\
\hline Other, non-Hispanic & $31(8 \%)$ & $32(8 \%)$ \\
\hline Hispanic & $48(12 \%)$ & $61(15 \%)$ \\
\hline \multicolumn{3}{|l|}{ Has children, $n(\%)$} \\
\hline Yes & $133(32 \%)$ & $138(34 \%)$ \\
\hline No & $277(68 \%)$ & $272(66 \%)$ \\
\hline \multicolumn{3}{|l|}{ Medical conditions, $n(\%)^{b}$} \\
\hline Yes & $263(64 \%)$ & $261(64 \%)$ \\
\hline None of the conditions listed & $147(36 \%)$ & $149(36 \%)$ \\
\hline \multicolumn{3}{|l|}{ Health insurance, $n(\%)^{c}$} \\
\hline Yes & $377(92 \%)$ & $372(91 \%)$ \\
\hline No/do not know/unsure & $31(8 \%)$ & $36(9 \%)$ \\
\hline Missing & 2 & 2 \\
\hline \multicolumn{3}{|l|}{ Household Internet access, $n(\%)$} \\
\hline Yes & $340(83 \%)$ & $321(78 \%)$ \\
\hline No & $70(17 \%)$ & $89(22 \%)$ \\
\hline \multicolumn{3}{|l|}{ Income, $n(\%)$} \\
\hline$<\$ 20,000$ & $41(10 \%)$ & $51(12 \%)$ \\
\hline$\$ 20,000-\$ 49,999$ & $112(27 \%)$ & $114(28 \%)$ \\
\hline$\$ 50,000-\$ 84,999$ & $103(25 \%)$ & $106(26 \%)$ \\
\hline$\geq \$ 85,000$ & $154(38 \%)$ & $138(34 \%)$ \\
\hline
\end{tabular}

aData were weighted to represent the general population of the United States. ${ }^{b}$ Could select one or more of the following medical conditions: arthritis, asthma or allergies, cancer, diabetes, gastrointestinal conditions, heart disease, high blood pressure, high cholesterol, migraines, osteoporosis, and stroke. 'Could select one or more of the following health-insurance options: private insurance paid for by self, private insurance paid for by employer (spouse or self), Medicaid, Medicare, veteran's health insurance, and other.

we used an interval regression (IR) model. ${ }^{24}$ The IR model conditioned respondents' willingness to pay based on the attributes of the information that respondents would be acquiring with their genomic status and respondents' personal characteristics. The IR model uses answers to the DBCV questions to identify intervals within which the respondents' willingness to pay is expected. Results from the IR model can be interpreted as the contribution of the characteristics of genomic information and respondents' personal characteristics to their willingness to pay for WGS information.
To determine which respondents were willing to acquire genomic information, we estimated a probit regression model relating a participation variable to personal characteristics.

\section{Study sample}

The survey was administered online to a general population sample of adults (21 years and older) in the United States. Participant recruitment occurred in two stages. First, GfK, a market-research company, recruited respondents by invitation through their Internet-based panel, KnowledgePanel. ${ }^{25}$ 
Table 3 Summary of rankings: most and least preferred option of who defines results included in the basic genomic report $(n=410)$

\begin{tabular}{lccccc} 
& & \multicolumn{3}{c}{$\begin{array}{c}\text { Chose as most } \\
\text { preferred }\end{array}$} & Total (least \\
\cline { 3 - 5 } & & Panel & Doctor & You & preferred) \\
\hline Chose as least preferred & Panel & 0 & 68 & 133 & 201 \\
& Doctor & 27 & 0 & 44 & 71 \\
& You & 66 & 72 & 0 & 138 \\
\hline Total (most preferred) & & 93 & 140 & 177 & 410 \\
\hline
\end{tabular}

KnowledgePanel is a probability-based Web panel designed to be representative of the United States population. It has been used extensively in research reported in more than 400 papers, articles, and books, including several studies on genetic testing, and is validated by the American Association for Public Opinion Research. ${ }^{25-27}$ GfK uses a modest incentive program for panel members to encourage participation, including entry into raffles or special sweepstakes with both cash rewards and other prizes. Households are provided with access to the Internet and a laptop if needed. Panel members were randomly invited to participate in our survey using residential addressbased sampling methods. E-mail reminders were sent to nonresponders four times.

A total of 873 individuals were invited to participate in the survey; 410 gave consent to participate and completed the survey in full (47\% response rate, Supplementary Appendix B online). This allowed for robust statistical analyses with a minimum acceptable level of statistical precision (standard error $<0.05)$.

\section{Ethics and consent}

Informed consent was obtained from respondents prior to beginning the survey. Ethics approval was obtained through the University of California-San Francisco Human Research Protection Program Committee on Human Research (1209652) and the University of Calgary Conjoint Health Research Ethics Board (13-1231).

\section{RESULTS}

Overall, respondents were similar to the general population of the United States, with the following exceptions: median age was higher (50 vs. 37 years), the proportion of males was higher (53 vs. $49 \%$ ), more were married or living with a partner (64 vs. $51 \%$ ), levels of postsecondary education were higher (64 vs. $58 \%$ ), and incomes were higher (Table 2). ${ }^{28,41}$ The median time taken to complete the survey was 22 minutes.

Regarding experiences with genomic testing (Supplementary Appendix C online), 7\% reported ever having undergone a genetic test and only $2 \%$ reported ever having their genome sequenced. When respondents were asked if they would want to learn if they had a gene variant that could lead to a fatal disease for which the medical treatment is currently unclear, $34 \%$ said they would want to have this information. These individuals were mostly males, had an average age of 47 years (SD: 16 a

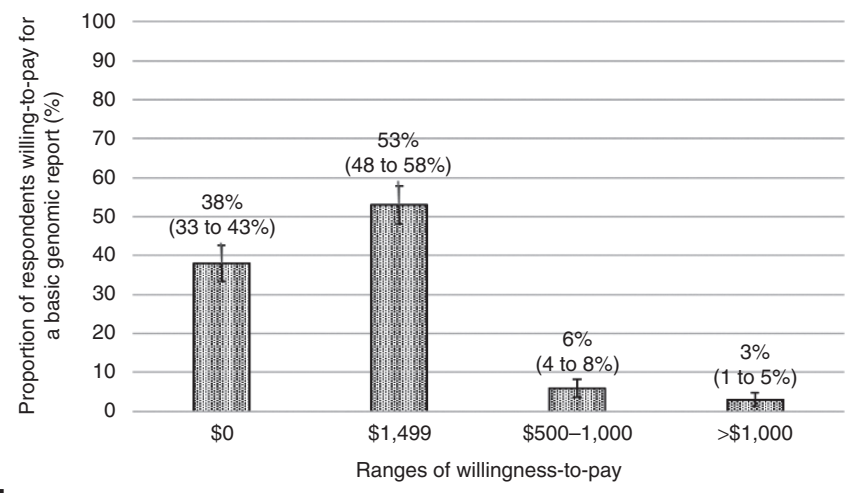

b

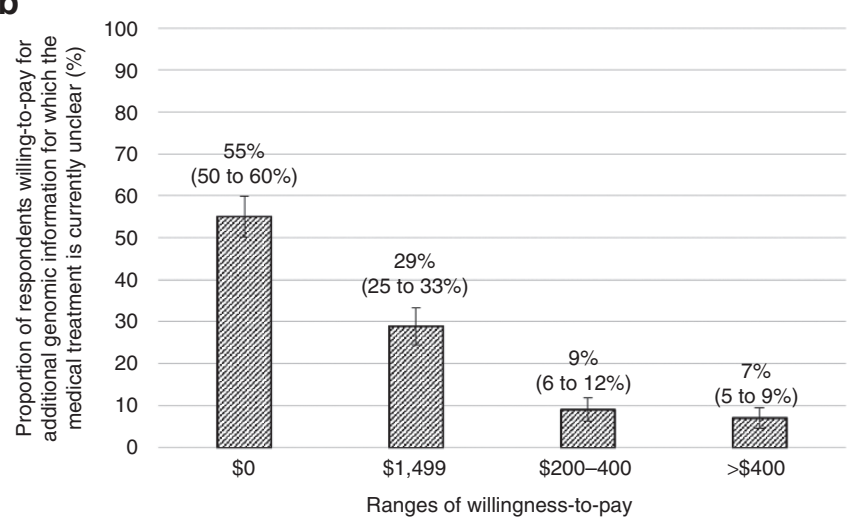

Figure 2 Distribution of respondents' $(n=410)$ willingness to pay. The options are (a) a basic genomic report that includes only actionable genomic status information and (b) additional genomic information for which the medical treatment is currently unclear.

years), were white (non-Hispanic), had at least some college education, and had a household income of $\$ 50,000$ or more. When respondents were asked if they would want to learn if they had a gene variant that could lead to severe, progressive memory loss that is not treatable, $48 \%$ indicated they would want to have this information. These individuals represented an even split of males and females, had an average age of 47 years (SD: 17 years), were white (non-Hispanic), had at least some college education, and had a household income of $\$ 50,000$ or more.

Deciding for themselves about what information is included in the basic genomic report was the most preferred option for $43 \%$ of respondents, and $34 \%$ said they would prefer that their primary-care physicians decided (Table 3 ). Only $23 \%$ of respondents said they would prefer that a panel of experts defined the information contained in the basic genomic report. We found no statistically significant effect of any individual characteristics that helped explain differences in the ranking of options.

A substantial proportion of respondents did not value obtaining genomic information included in the basic report (38\%; 95\% CI: 33-43\%) or genomic information for which the medical treatment is currently unclear (55\%; 95\% CI: 50-60\%), even if this information was available at no cost (Figure 2). For the basic WGS report, most respondents (53\%; 95\% CI: 48-58\%) 
were willing to pay up to $\$ 500$; only $9 \%$ were willing to pay more than $\$ 500$ (Figure 2a). Among respondents who expressed interest in obtaining genomic information in the basic report $(n=253)$, the average willingness-to-pay estimate was $\$ 299$ (SD: $\$ 86 ; P<0.01)$. None of the respondent characteristic variables in the regression model (preference for who decides what results to include in a report, interest in knowing about gene variants related to fatal health problems for which the medical treatment is currently unclear or to memory loss and function, having children younger than 18 years old, household income, gender, race, previous genetic testing, and time it took to complete the survey) was significantly associated with willingness to pay for the basic report.

For the genomic information for which the medical treatment is currently unclear, $29 \%$ (95\% CI: $25-33 \%$ ) were willing to pay up to $\$ 200$ and $16 \%$ were willing to pay more than $\$ 200$ (Figure 2b) for this information. Among respondents who expressed interest in obtaining this genomic information $(n=184)$, the average willingness to pay was $\$ 180$ (SD: $\$ 83$; $P<0.05)$. Respondent characteristics, such as interest in knowing about fatal health problems for which the medical treatment is currently unclear $(P<0.05)$ and history of previous genetic testing $(P<0.01)$, were associated with a higher likelihood of being willing to pay. No other respondent characteristic variables included in the regression model (chance of having a gene variant for which the medical treatment is currently unclear, chance of death in the next 10 years from a health problem, preference for who decides what results to include in a report, interest in knowing about gene variants related to memory loss and function for which the medical treatment is currently unclear, having children younger than 18 years old, household income, gender, race, time it took to complete the survey, and interaction terms) were significantly associated with willingness to pay for this additional genomic information.

Respondents' willingness to obtain genomic information was positively associated with interest in knowing about gene variants related to fatal health problems for which the medical treatment is currently unclear $(P<0.01)$ and problems that would significantly affect quality of life (e.g., permanent loss of memory and function; $P<0.01$ ). Respondents who reported preferring control over the type of genomic information included in the basic genomic report were more likely to want to acquire information on gene variants for which the medical treatment is currently unclear, if offered $(P<0.01)$. Being male was significantly associated with interest in obtaining additional genomic information for which the medical treatment is currently unclear $(P<0.05)$ but not significantly associated with willingness to obtain the basic report. No other variables included in the regression model (preference for doctor deciding what results to include in a report, having children younger than 18 years old, household income, previous genetic testing, and race) were significantly associated with respondents' interest in obtaining WGS information. The model controlled for the influence of respondents $(n=29)$ who completed the survey more quickly than expected if they were reading and considering all the responses.

\section{DISCUSSION}

Assessing the value of WGS is complex because it is a technology that provides multiple results with varying levels of clinical usefulness. Willingness to pay, as measured by contingent valuation, can be used to reflect the value of WGS information. There is limited evidence regarding willingness to pay for WGS information depending on whether that information is medically actionable or regarding who should decide what results are included and returned in a WGS report. We addressed this gap by eliciting preferences for who defines which WGS results are included in a WGS report and by estimating the value of WGS information using contingent-valuation methods.

In exploring who decides which results are included in a basic WGS report, we found that most individuals (43\%) would prefer to decide themselves. Although our study uniquely addressed the issue of who should decide, our findings are supported by other findings that people, regardless of their health status, would generally like a choice about the WGS information they receive, and many clinicians believe that people should have a choice about the results they receive (actionable or not). ${ }^{17-19,29}$ Concerns have been raised regarding the feasibility of sharing WGS results, specifically with regard to the large amount of time and resources required to review and discuss all possible results in a genomic report, ${ }^{30,31}$ as well as the difficulty of counseling patients about all results in a report, or choosing a subset of actionable genes for analysis, when this information is constantly evolving. ${ }^{7}$ These are important considerations given that the general population has limited knowledge and understanding of personalized medicine, ${ }^{32}$ and genomic policy experts have expressed concerns regarding genomic literacy. ${ }^{33}$ Furthermore, although people are currently able to opt out of the analysis of genes unrelated to the indication for testing, they are not allowed to opt in. ${ }^{7}$ Our findings suggest that some people would be better off, in terms of personality utility (as reflected by their willingness to pay), if they were also allowed to make an informed decision to opt to receive genomic information for which the medical treatment is currently unclear. This may be associated with getting their affairs in order if they have a gene variant that increases the chance of death or they hope that information on long-term risks may be actionable in the future.

In our nationally representative sample, we found that some respondents would not want genomic information even if it were free. If they were interested in obtaining genomic information, then respondents were willing to pay more for the basic WGS report (\$299; actionable findings) than for the additional genomic findings for which the medical treatment is currently unclear (\$180), suggesting that respondents valued the prophylactic or therapeutic benefits of the information in the WGS report. The characteristics of the genomic information (prevalence, severity of the health problems that the variant might cause, and risk of death in the next 10 years associated with 
having the gene variant) did not seem to influence the amount respondents were willing to pay for additional genomic information, suggesting that the information itself, not the outcomes associated with the genomic information, was considered to be of value.

Previous research has demonstrated varying levels of interest in undergoing $\mathrm{WGS}^{34}$ and a wide range of estimates for willingness to pay to undergo genetic or genomic testing. In Canada and the United Kingdom, 30-80\% of individuals are willing to undergo genetic or genomic testing if it is free of charge and $5-37 \%$ are willing to pay up to approximately $\$ 500$ to undergo testing, with few willing to pay more than $\$ 500 .{ }^{35-37}$ Age and interest in undergoing genetic or genomic testing influence willingness to pay. ${ }^{35,36}$

Having used contingent-valuation methods to reduce the potential bias of eliciting willingness to pay directly, our findings are generally consistent in the context of previous studies on preferences and value of complex genetic information. For example, Ries et al. explored willingness to pay for genetic testing in a Canadian general population sample using a cost scale $(\$ 0, \$ 1-499, \$ 500-1,999, \$ 2000+)$ and found that most people are not willing to pay more than $\$ 500$ to learn about manageable diseases. ${ }^{36}$ Additionally, $48 \%$ would not pay anything to learn about their risk of developing a serious condition, and $32 \%$ would pay up to $\$ 500$ for this information. ${ }^{36}$

Regier et al. ${ }^{20}$ focused on information derived from secondary genomic findings and estimated willingness to pay using discrete-choice methods in a sample of adults from the general population. In a scenario that explores willingness to pay for information that may or may not be actionable, the mean amount respondents were willing to pay was $\$ 280 .{ }^{20}$ These methods were different from those used in our study, and the amount respondents were willing to pay was greater than our findings ( $\$ 280$ versus $\$ 180$ ) but similar in magnitude.

Implementation of WGS in a clinical setting has been limited partly by the lack of coverage of test costs by insurance companies and the inability of some patients to pay the out-ofpocket costs. ${ }^{11}$ There is variation in cost coverage depending on the insurance company and type of testing. However, coverage policies are being updated as use of this technology increases. ${ }^{11}$

Although our study has several strengths, there are some limitations. First, there are limitations associated with online research panels, such as possible incentive bias. However, this method and use of incentives are common. Research using data from online surveys has demonstrated validity and reliability that are comparable to those using traditional methods..$^{38,39}$ Second, although contingent valuation is well established, this approach does not inform questions as to the specific aspects of the service that are valued. To determine how different aspects of services are valued, decompositional approaches such as conjoint analysis are needed. Conjoint analysis characterizes a service based on multiple attributes and elicits trade-offs among those attributes. ${ }^{40}$

Our results provide evidence that individuals in the general population value actionable genetic information more than genomic information for which the medical treatment is currently unclear, as reflected by their willingness to pay, but some respondents did not value any genetic information, as demonstrated by their lack of interest, even if it were free. Furthermore, although the original ACMG guidelines for genomic testing were based on input from experts, we found that people prefer to decide themselves what WGS information is reported. These findings support the more recent ACMG policy statement that patients should be able to opt out of genetic analysis unrelated to the indication for testing. Our findings indicate that some people would be better off, in terms of personal utility, if they were also allowed to make an informed decision to opt in to receiving genomic information for which the medical treatment is currently unclear; however, for some, negative value may be associated with the information generated from these results. However, if a person chooses to opt to receive this information, then decision makers need to consider who should pay and which individuals would be eligible to opt in given the potential financial impact on the health-care system. This suggests that patient preferences should be used to inform policies and consent processes about WGS testing and how results are reported in the future because negative value may be associated with information generated from these results.

\section{SUPPLEMENTARY MATERIAL}

Supplementary material is linked to the online version of the paper at http://www.nature.com/gim

\section{ACKNOWLEDGMENTS}

This study was partially funded by an NHGRI grant to K.A.P. (R01HG007063), an NCl grant to the UCSF Helen Diller Family Comprehensive Cancer Center (5P30CA082013-15), and the UCSF Mount Zion Health Fund. We thank Denise Lautenbach, Jill Oliver Robinson, and the MedSeq study team (U01-HG006500) for their advice and guidance with developing our survey and recruiting participants for pretest interviews. We thank GfK for their assistance in programming and hosting our online survey.

\section{DISCLOSURE}

D.A.M. is supported by a Canada Research Chair, Health Services and Systems Research, and the Arthur J.E. Child Chair in Rheumatology Outcomes Research. She performs ad hoc consulting to support health economics and outcomes research for Optum Insight. The other authors declare no conflict of interest.

\section{REFERENCES}

1. Green RC, Berg JS, Berry GT, et al. Exploring concordance and discordance for return of incidental findings from clinical sequencing. Genet Med 2012;14: 405-410.

2. Vassy JL, Lautenbach DM, McLaughlin HM, et al.; MedSeq Project. The MedSeq Project: a randomized trial of integrating whole genome sequencing into clinical medicine. Trials 2014;15:85

3. Green RC, Rehm HL, Kohane IS. Clinical genome sequencing. In: Ginsburg GS Willard HF, eds. Genomic and Personalized Medicine. 2nd edn. Academic Press: London, 2013:102-122.

4. Biesecker LG, Green RC. Diagnostic clinical genome and exome sequencing. $N$ Engl J Med 2014;370:2418-2425. 
5. Bamshad MJ, Ng SB, Bigham AW, et al. Exome sequencing as a tool for Mendelian disease gene discovery. Nat Rev Genet 2011;12:745-755.

6. Green RC, Berg JS, Grody WW, et al.; American College of Medical Genetics and Genomics. ACMG recommendations for reporting of incidental findings in clinical exome and genome sequencing. Genet Med 2013;15:565-574.

7. ACMG Board of Directors. ACMG policy statement: updated recommendations regarding analysis and reporting of secondary findings in clinical genome-scale sequencing. Genet. Med. 2014;17:68-69.

8. McGuire AL, Burke W. An unwelcome side effect of direct-to-consumer personal genome testing: raiding the medical commons. JAMA 2008;300:2669-2671.

9. Kohane IS, Masys DR, Altman RB. The incidentalome: a threat to genomic medicine. JAMA 2006;296:212-215.

10. Gray SW, Martins Y, Feuerman LZ, et al.; CSER Consortium Outcomes and Measures Working Group. Social and behavioral research in genomic sequencing: approaches from the Clinical Sequencing Exploratory Research Consortium Outcomes and Measures Working Group. Genet Med 2014;16:727-735.

11. Chakradhar S. Insurance companies are slow to cover next-generation sequencing. Nat Med 2015;21:204-205.

12. Berg JS, Khoury MJ, Evans JP. Deploying whole genome sequencing in clinical practice and public health: meeting the challenge one bin at a time. Genet Med 2011;13:499-504.

13. Ramos EM, Din-Lovinescu C, Berg JS, et al. Characterizing genetic variants for clinical action. Am J Med Genet C Semin Med Genet 2014;166C:93-104.

14. Feero WG, Wicklund $C$, Veenstra DL. The economics of genomic medicine: insights from the IOM Roundtable on Translating Genomic-Based Research for Health. JAMA 2013;309:1235-1236.

15. Douglas MP, Ladabaum U, Pletcher MJ, Marshall DA, Phillips KA. Economic evidence on identifying clinically actionable findings with whole-genome sequencing: a scoping review. Genet Med 2016;18:111-116.

16. Mitchell RC, Carson RT. Using Surveys to Value Public Goods: The Contingent Valuation Method. Resources for the Future: New York, 1993.

17. Schneider J, Goddard KB, Davis J, et al. "Is It Worth Knowing?" Focus group participants' perceived utility of genomic preconception carrier screening. J Genetic Counseling 2016;25:135-145.

18. Holm IA, Savage SK, Green RC, et al. Guidelines for return of research results from pediatric genomic studies: deliberations of the Boston Children's Hospital Gene Partnership Informed Cohort Oversight Board. Genet Med 2014;16:547-552.

19. Klitzman R, Appelbaum PS, Fyer A, et al. Researchers' views on return of incidental genomic research results: qualitative and quantitative findings. Genet Med 2013;15:888-895

20. Regier DA, Peacock SJ, Pataky R, et al. Societal preferences for the return of incidental findings from clinical genomic sequencing: a discrete-choice experiment. CMAJ 2015;187:E190-E197.

21. Presser S, Couper MP, Lessler JT, et al. Methods for testing and evaluating survey questions. Public Opin Q 2004;68:109-130.

22. Klose T. The contingent valuation method in health care. Health Policy 1999;47:97-123.

23. Long JS, Freese J. Regression Models for Categorical Dependent Variables Using Stata. 2nd edn. Stata Press: College Station, TX, 2006.
24. Amemiya T. Regression analysis when the dependent variable is truncated normal. Econometrica 1973;41:997-1016.

25. Baker L, Bundorf $\mathrm{M}$, Singer $\mathrm{S}$, Wagner T. Validity of the Survey of Health and the Internet, and Knowledge Networks' Panel and Sampling. Stanford University: Stanford, CA. 2003.

26. Baker L, Wagner TH, Singer S, Bundorf MK. Use of the Internet and e-mail for health care information: results from a national survey. JAMA 2003;289: 2400-2406.

27. Baker R, Blumberg SJ, Brick JM, et al. Research synthesis: AAPOR report on online panels. Public Opin Q 2010;74:711-781.

28. DeNavas-Walt C, Proctor B, Smith J, U.S. Census Bureau. Current Population Reports: Income, Poverty, and Health Insurance Coverage in the United States 2012. Washington, DC 2013. https://www.census.gov/prod/2013pubs/p60245.pdf.

29. Graves KD, Sinicrope PS, McCormick JB, Zhou Y, Vadaparampil ST, Lindor NM. Public perceptions of disease severity but not actionability correlate with interest in receiving genomic results: nonalignment with current trends in practice. Public Health Genomics 2015;18:173-183.

30. Dewey FE, Grove ME, Pan C, et al. Clinical interpretation and implications of whole-genome sequencing. JAMA 2014;311:1035-1045.

31. Dorschner Michael O, Amendola Laura M, Turner Emily H, et al. Actionable, Pathogenic Incidental Findings in 1,000 Participants' Exomes. The American Journal of Human Genetics. 2013;93:631-640.

32. Garfeld S, Douglas MP, MacDonald KV, Marshall DA, Phillips KA. Consumer familiarity, perspectives and expected value of personalized medicine with a focus on applications in oncology. Per Med 2015;12: $13-22$.

33. Johnson KJ, Gehlert S. Return of results from genomic sequencing: a policy discussion of secondary findings for cancer predisposition. J Cancer Policy 2014;2:75-80.

34. Dodson DS, Goldenberg AJ, Davis MM, Singer DC, Tarini BA. Parent and public interest in whole-genome sequencing. Public Health Genomics 2015;18: 151-159.

35. Bosompra K, Ashikaga T, Flynn BS, Worden JK, Solomon L. Psychosocial factors associated with the public's willingness to pay for genetic testing for cancer risk: a structural equations model. Health Educ Res 2001;16:157-172.

36. Ries NM, Hyde-Lay R, Caulfield T. Willingness to pay for genetic testing: a study of attitudes in a Canadian population. Public Health Genomics 2010;13: 292-300.

37. Cherkas LF, Harris JM, Levinson E, Spector TD, Prainsack B. A survey of UK public interest in internet-based personal genome testing. PLoS One 2010;5:e13473.

38. Evans JR, Mathur A. The value of online surveys. Internet Research 2005;15:195-219.

39. Eysenbach G, Wyatt J. Using the Internet for surveys and health research. J Med Internet Res 2002;4:E13.

40. Bridges JF, Hauber AB, Marshall D, et al. Conjoint analysis applications in healtha checklist: a report of the ISPOR Good Research Practices for Conjoint Analysis Task Force. Value Health 2011;14:403-413.

41. U.S. Census Bureau. Age and Sex Composition in the United States: 2012. 2012; https://www.census.gov/population/age/data/2012comp.html. Accessed 2015-Sept-10. 